\title{
Study on Desorption Experiment and Desorption Model of Deep Shale Gas Containing Water
}

\author{
Zuping Xiang $(\mathbb{D}$, Yangyang Ding $\mathbb{B}$, Xiang Ao $\mathbb{D}$, Zehua Cheng $\mathbb{D}$, Qianhua Xiao $\mathbb{i}$, \\ Zhezhi Liu $\mathbb{D}$, Shijie Zhu $\mathbb{D}$, and Zhonghua Chen
}

College of Petroleum and Natural Gas Engineering, Chongqing University of Science and Technology, NJ 401331, Chongqing, China

Correspondence should be addressed to Yangyang Ding; 2711800388@qq.com

Received 10 July 2021; Accepted 13 August 2021; Published 1 September 2021

Academic Editor: Xin Cai

Copyright (C) 2021 Zuping Xiang et al. This is an open access article distributed under the Creative Commons Attribution License, which permits unrestricted use, distribution, and reproduction in any medium, provided the original work is properly cited.

In this work, the methane desorption isothermal curves at different water contents on deep sampled from Western Chongqing of China were measured at pressures up to $65 \mathrm{MPa}$ and at $130^{\circ} \mathrm{C}$ by the volumetric method. In the first instance, the desorption increases with the decrease of pressure, the adsorbed gas desorbs slightly with decreasing pressures from 65 to $30 \mathrm{MPa}$. When the pressure drops to 30-20 MPa, the desorption rate increases rapidly with the decrease of pressure and the desorption curve begins to separate from the adsorption curve, resulting in desorption hysteresis. At last, when the pressure is lower than $20 \mathrm{MPa}$, the desorption increases almost linearly with the further decrease of pressure, but eventually there will be some adsorbed gas which cannot be desorbed to form residual adsorbed gas. After that, the isotherm desorption data of $\mathrm{CH}_{4}$ was fitted using the improved desorption model. The fitting results showed that the improved desorption model can be used to describe the desorption process of deep shale gas containing water and has a strong applicability. In addition, the critical desorption pressure increases with increasing water content. When the water content is lower than $1 \%$, the effect of the water content on the desorption of deep shale gas increases rapidly with increasing water content, as well as when the water content is greater than $1 \%$, the impact changes slowly.

\section{Introduction}

The geological shale gas resources in China are $123 \times 10^{12} \mathrm{~m}^{3}$, of which the amount of resources that can be exploited using the current technology is $21.84 \times 10^{12} \mathrm{~m}^{3}$ [1], and the deep shale gas resources at depths of over $3500 \mathrm{~m}$ account for more than $65 \%$ of the total resources [2]. The shale gas resources in China's Sichuan Basin and its surrounding areas account for $46.56 \%$ of China's shale gas geological resources [3], of which deep shale gas accounts for more than 69\% [4]. Therefore, in recent years, the proportion of deep shale gas exploration and development work in China has gradually increased and has achieved certain results [5].

In shale reservoirs, gas is mainly stored in the form of adsorbed gas, free gas, and dissolved gas [6], and the adsorbed gas usually accounts for $20-85 \%$ of the total gas $[7,8]$. In the early stage of exploitation, free gas is used as the main gas source and is rapidly exploited. And, massive desorption in the adsorbed gas in the reservoir when the reservoir pressure drops to a certain extent [9]. Consequently, it is of great significance to investigate the desorption law of $\mathrm{CH}_{4}$ in shale to evaluate the exploitation potential and for the productivity prediction of shale gas $[10,11]$. However, the desorption of shale gas is affected by many factors such as temperature, pressure, and water $[12,13]$. During the process of fracturing transformation, the reservoir's water content increases because of the large amount of fracturing fluid retained [14], and the original water content state is disrupted. The entry of the fracturing fluid leads to a change in the desorption of shale gas during depressurization [15]. Most researchers have studied the influence of the water content on shale gas adsorption. For example, Zhang [16] tested the adsorption of water-bearing shale gas under the experimental conditions of $30^{\circ} \mathrm{C}$ and 
$50^{\circ} \mathrm{C}$ and $0-25 \mathrm{MPa}$ by improving the volumetric method, and it is found that the maximum adsorption capacity decreases with the increase of water content. Yang et al. [17] measured the isothermal adsorption curves of water-bearing shale gas at $20^{\circ} \mathrm{C}$ and $85^{\circ} \mathrm{C}$ and at $0-30 \mathrm{MPa}$ using the volumetric method. In 2018, Shen et al. [18] measured the adsorption curve of shale gas at $95.6^{\circ} \mathrm{C}$ and $50 \mathrm{MPa}$. It was found that the fitting error of the Langmuir model was greater when the pressure was higher than $25 \mathrm{MPa}$. Duan et al. [19] studied shale samples from the Longmaxi Formation in the Sichuan Basin, China. They measured the isothermal adsorption curves of shale gas at a maximum pressure of $50 \mathrm{MPa}$ using the volumetric method. Under different pressures, the pore structure will also change, which will affect the desorption and flow of gas [20,21]. The pressure of deep shale reservoir is generally higher than $60 \mathrm{MPa}$, and the average formation temperature is about $130^{\circ} \mathrm{C}$ [22]. However, the temperature and pressure conditions of the existing experimental studies are not consistent with the conditions in deep shale gas reservoirs. In addition, there are few studies which focus on the shale gas desorption under the water content condition.

In this study, isothermal desorption experiments were conducted on shale samples under temperature up to $130^{\circ} \mathrm{C}$ and gas pressure up to $65 \mathrm{MPa}$. In addition, combining these experiments and an improved desorption model based on the D-A model and the gas-solid adsorption model in a tube pore system, the desorption law and desorption model of shale samples with different water contents under high-temperature and high-pressure conditions were studied.

\section{Theories}

2.1. D-A Model. The D-A (Dubinin-Astakhov) model $[23,24]$ is suitable for describing the adsorption and desorption of shale gas under high-temperature and highpressure conditions [22]. In this work, the D-A model (equation (1)) was improved to describe the desorption of deep shale gas under different water content conditions:

$$
V_{\mathrm{ad}}=V_{0} \exp \left\{-\left[\frac{\mathrm{RT}}{E} \ln \left(\frac{P_{0}}{P}\right)\right]^{k}\right\},
$$

where $V_{\text {ad }}$ is the absolute adsorption capacity of the adsorbent $\left(\mathrm{m}^{3} / t\right), V_{0}$ is the maximum adsorption capacity of the micropores $\left(\mathrm{m}^{3} / t\right), E$ is the characteristic energy of the adsorption $(\mathrm{J} / \mathrm{mol}), R$ is the gas constant $(8.314 \mathrm{~J} /(\mathrm{mol} \cdot \mathrm{K})), T$ is the temperature $(\mathrm{K}), P_{0}$ is the saturated vapor pressure $(\mathrm{MPa}), P$ is the test pressure of experimental $(\mathrm{MPa})$, and $k$ is the coefficient of the distribution of the adsorption potential on the adsorbent surface (taken as 2-6).

Because the temperature and pressure of the experiment are higher than the critical temperature and pressure of the $\mathrm{CH}_{4}$, the adsorption of shale gas was supercritical adsorption, and the saturated vapor pressure had no practical physical significance, so the virtual saturated vapor pressure $\left(P^{0}\right)$ (equation $(2)$ ) was used to replace the saturated vapor pressure $\left(P_{0}\right)[25]$ :

$$
P^{0}=P_{c}\left(\frac{T}{T_{c}}\right)^{m}
$$

where $P^{0}$ is the virtual saturated vapor pressure $(\mathrm{MPa}), P_{c}$ is the critical pressure of methane $(4.59 \mathrm{MPa}), T_{c}$ is the critical temperature of methane $(190.56 \mathrm{~K})$, and $m$ is the adsorption system coefficient.

2.2. Desorption Model considering Water Content. According to research from Li et al. [26], the water molecules adsorbed on the surface of porous media will form a water film. The gas-solid adsorption of circular pores is used to simulate the adsorption state of gas in the actual matrix pores. If only the adsorption between gas and solid is considered. The specific model is described as follows.

Assuming the water molecules coverage on the pore wall at $\theta_{w}$, then

$$
0 \leq \theta_{w} \leq 1
$$

Thus, as can be seen from Figure 1(a), the water molecules completely cover the surface of the pore. When the gas-liquid adsorption is not considered, the gas is completely in the free state. It is assumed that the saturation of the pore water is the critical water saturation $S_{\mathrm{cv}}$, and thus, the water saturation in the pores can be expressed by equation (4). As can be seen from Figure 1(b), if the water molecules do not completely cover the surface of pore of the matrix, then the water saturation is set as $S_{w}$, and thus, the water saturation can be expressed by equation (5). Then, by transforming equations (4) and (5) [27], the relationship between the water saturation and the water coverage in the nanopores is obtained using equation (6). Then, the relationship between the actual adsorption capacity $V_{0}$ and the maximum adsorption capacity $V_{1}$ and the surface coverage $\theta_{w}$ of the water can be expressed by equation (7):

$$
\begin{aligned}
& S_{\mathrm{cv}}=\frac{r^{2}-(r-0.4)^{2}}{r^{2}}, \\
& S_{w}=S_{\mathrm{cv}} \theta_{w}, \\
& \theta w=S_{w} \cdot S_{\mathrm{cv}}^{-1}=S_{w}\left[\frac{r^{2}-(r-0.4)^{2}}{r^{2}}\right]^{-1}, \\
& V_{0}=\left(1-\theta_{w}\right) V_{1} .
\end{aligned}
$$

By combining equations (1), (2), and (7), the desorption model (equation (8)) for deep shale gas-containing water considering the influence of water was obtained:

$$
V_{\mathrm{ad}}=\left(1-\theta_{w}\right) V_{1} \exp \left\{-\left[\frac{\mathrm{RT}}{E} \ln \left(\frac{P_{c}\left(T / T_{c}\right)^{m}}{P}\right)\right]^{\kappa}\right\} .
$$

In the depressurization and desorption of the adsorbed gas, the amount of adsorbed gas decreases gradually. In fact, the amount of desorption in each pressure stage is the difference in the adsorption capacities at the two pressure points. In actual production, when the residual pressure is reached, the adsorbed gas in the reservoir cannot be 


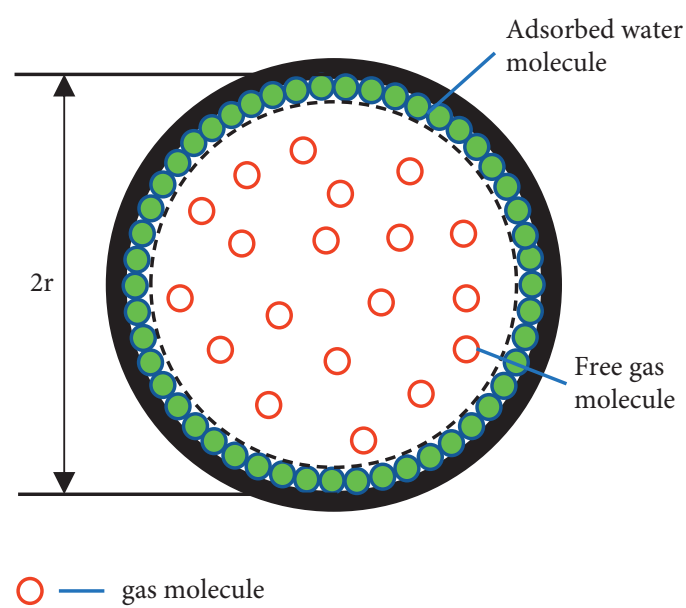

(a)

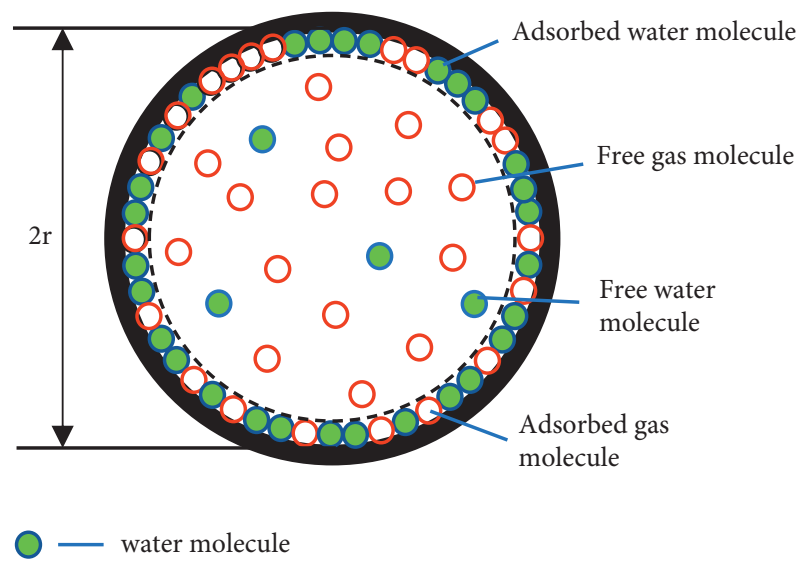

(b)

Figure 1: Diagram of gas-solid adsorption in the pores of a circular tube. (a) Water molecules completely cover the pore wall. (b) Water molecules do not completely cover the pore wall.

completely desorbed. Therefore, the parameter $V_{c}$ is introduced here, which is the quantity of adsorbed gas under the residual pressure [28]. Based on the conversion from adsorption to desorption in the Langmuir isothermal adsorption model [11], equation (8) was amended to

$$
V_{\mathrm{ad}}=\left(1-\theta_{w}\right) V_{1} \exp \left\{-\left[\frac{\mathrm{RT}}{E} \ln \left(\frac{P_{c}\left(T / T_{c}\right)^{m}}{P}\right)\right]^{\kappa}\right\}+V_{c},
$$

where $r$ is the pore radius of the matrix $(\mathrm{nm})$ and $V_{1}$ is the maximum adsorption capacity of the gas at $\theta_{w}=0\left(\mathrm{~m}^{3} / t\right)$.

\section{Experimental Section}

3.1. Shale Sample Preparation. Shale outcrop rock samples were collected from the Wufeng and Longmaxi Formations in Western Chongqing and were prepared according to the coal sample preparation method GB/T474 [29]. An ST-E200 table jaw crusher was used to crush the shale samples, and the 30-80 mesh powder was screened out. Then, the powder was dried in a constant temperature oven at $80^{\circ} \mathrm{C}$ for $48 \mathrm{~h}$. The preparation of balanced water samples was conducted according to Section 6.3 of standard GB/T19560-2008. The water-bearing shale samples with different water contents were prepared using supersaturated $\mathrm{NaCl}$ solution $(\mathrm{RH}=0.75$, where $\mathrm{RH}$ is the relative humidity of the air, which refers to the ratio of the vapor pressure of water in the air to the saturated vapor pressure of water at the same temperature and pressure) and supersaturated $\mathrm{K}_{2} \mathrm{SO}_{4}$ solution $(\mathrm{RH}=0.98)$. The equilibrium water content is the ratio of the mass increment of the sample after equilibrium water to the mass of the sample after equilibrium water, and the basic information about the samples after preparation is presented in Table 1.

3.2. Experimental Instruments and Testing Principles. The isothermal desorption experiment of deep shale gas was carried out using an IAA-1020 shale isothermal adsorption instrument (Figure 2). The pressure sensor used in the experiment was a high-temperature resistant sensor (Honeywell, American, model TJE, range: $0-100 \mathrm{MPa}$ and accuracy: \pm 0.001$)$ and the PT100 temperature sensor (Shiye instrument, China, model WZP-035, range: $-50-200^{\circ} \mathrm{C}$ and accuracy: $\pm 0.1^{\circ} \mathrm{C}$ ). In this study, the isothermal adsorption and desorption experiments were conducted at $130^{\circ} \mathrm{C}$ and $65 \mathrm{MPa}$, and single component methane was used as the adsorption phase.

Testing principle: before adsorption equilibrium, the amount of free gas in the reference cylinder was expressed by equation (10), the amount of free gas in the sample cylinder was expressed by equation (11), and the volume of free space was expressed by equation (12). After adsorption equilibrium, the total amount of free gas in the free space was expressed by equation (13):

$$
\begin{gathered}
n_{c}=\frac{P_{c} V_{c}}{Z_{c} \mathrm{RT}_{c}}, \\
n_{y}=\frac{P_{y} V_{y}}{Z_{y} \mathrm{RT}_{c}}, \\
V_{z}=V_{c}+V_{y}, \\
n_{B}=\frac{P_{B} V_{Z}}{Z_{B} \mathrm{RT}_{B}} .
\end{gathered}
$$

Therefore, after the $i$ th pressurization, the adsorption gas increment was expressed by equation (15):

$$
\begin{aligned}
& \Delta n_{i}=n_{c i}+n_{y i}-n_{B i}, \\
& \Delta n_{i}=\frac{P_{c i} V_{c}}{Z_{c i} \mathrm{RT}_{c i}}+\frac{P_{y i} V_{y}}{Z_{y i} \mathrm{RT}_{c i}}-\frac{P_{B i} V_{Z}}{Z_{B i} \mathrm{RT}_{B i}} .
\end{aligned}
$$

Then, the total amount of gas adsorbed measured for the $i$ th pressurization was expressed by

$$
n_{\text {toal }}=\sum_{i=1}^{i} \Delta n_{i} .
$$


TABLE 1: Basic information about the shale samples.

\begin{tabular}{|c|c|c|c|c|}
\hline Sample number & Sample test quality $(\mathrm{g})$ & Test temperature $\left({ }^{\circ} \mathrm{C}\right)$ & Horizon & Equilibrium water content (\%) \\
\hline \multirow{3}{*}{ GBW-1 } & 121.613 & 130 & \multirow{3}{*}{ Wufeng formation } & 0 \\
\hline & 121.857 & 130 & & $0.71(\mathrm{RH}=0.75)$ \\
\hline & 122.506 & 130 & & $2.87(\mathrm{RH}=0.98)$ \\
\hline \multirow{3}{*}{ LZX-1 } & 133.144 & 130 & \multirow{3}{*}{ Longmaxi formation } & 0 \\
\hline & 133.416 & 130 & & $0.57(\mathrm{RH}=0.75)$ \\
\hline & 134.143 & 130 & & $2.53(\mathrm{RH}=0.98)$ \\
\hline
\end{tabular}

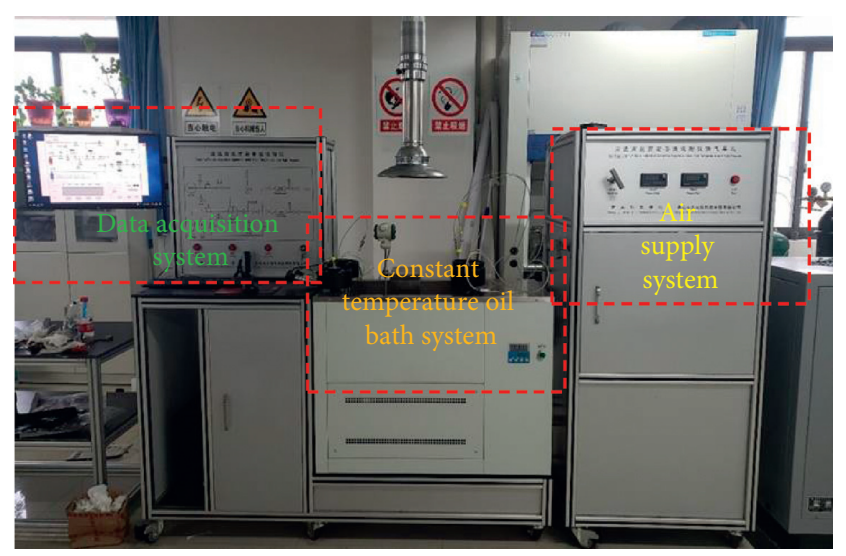

Figure 2: Shale high-temperature and high-pressure isothermal adsorption instrument.

During the desorption, the total amount of gas desorption measured at the $j$ th time was expressed by

$$
n_{\mathrm{de}}=n_{\text {all }}-n_{\text {toal }} \cdot
$$

At present, the adsorption capacity of shale gas measured using the volumetric method or the gravimetric method is defined as the excess adsorption capacity (it can be directly measured by the gravimetric method or the volumetric method, which is the adsorption capacity of the actual adsorption phase density minus the gas phase density), and there is a large deviation in the absolute adsorption capacity at high pressures [30]. Researchers usually assume that the density and volume of the adsorption phase [31,32], and then, the absolute adsorption capacity is calculated using the relationship between the excess adsorption capacity and the absolute adsorption capacity. However, the former requires that the density of the adsorption phase remain unchanged after adsorption saturation, while the latter requires that the volume of the adsorption phase remain unchanged after adsorption saturation. However, as the pressure changes, the adsorption capacity will inevitably change, and the density and volume of the adsorption gas will also change. Therefore, there are great limitations and deviations when calculating the absolute adsorption capacity (actual adsorption capacity of the solid-gas adsorption system) by assuming that the density and volume of the adsorption phase must be the same.

In this study, the free space volume (in the confined space for adsorption desorption experiment, except the volume occupied by the sample skeleton, the remaining space is the free space volume) at every two adjacent test pressure points in the experiment was modified using the method of Li et al. [13]. It was assumed that the sum of the molecular volumes of the adsorbed gas at the previous pressure point of each pressure stage was the free space volume occupied by the adsorbed gas, and then, the free space volume at each pressure point was corrected. The specific amendments are as follows. The free space volume $V_{\mathrm{Z} 1}$ of the first test point is the exact value ( $V_{\mathrm{Z} 1}$ is measured by using inert gas helium, which is not adsorbed by rock samples, so the measured free space volume is the accurate value), and the free space volume $V_{\mathrm{zi}}$ of the next test point is the free space volume $V_{\mathrm{Z} 1}$ of the first test point minus the absolute adsorption capacity $V_{i-1}$ under the previous test pressure. It is expressed by equations (18) and (19):

$$
\begin{gathered}
V_{Z i}=V_{Z 1}-V_{i-1}, \quad i>1, \\
V_{i-1}=n_{i-1} \times N_{A} \times V_{\text {methane }} .
\end{gathered}
$$

Equation (15) can be amended to

$$
\Delta n_{i}=\frac{P_{c i} V_{c}}{Z_{c i} \mathrm{RT}_{c i}}+\frac{P_{y i}\left(V_{Z \mathrm{i}}-V_{c}\right)}{Z_{y i} \mathrm{RT}_{c i}}-\frac{P_{B i} V_{Z i}}{Z_{B i} \mathrm{RT}_{B i}}
$$

where $P_{c i}$ is the initial pressure of the reference cylinder at the $i$ th point $(\mathrm{MPa}), P_{y i}$ is the initial pressure of the sample cylinder at the $i$ th point $(\mathrm{MPa}), P_{B i}$ is the balance of the overall pressure at the $i$ th point $(\mathrm{MPa}), T_{c i}$ is the initial temperature at the $i$ th point $(\mathrm{K}), T_{B i}$ is the temperature at the end of the pressure balance at the $i$ th point $(\mathrm{K}), Z_{c i}$ is the gas compression coefficient at temperature $T_{c i}$ at the $i$ th point, $Z_{B i}$ is the gas compression coefficient at the equilibrium temperature $T_{B i}, V_{c}$ is the reference cylinder volume $\left(\mathrm{cm}^{3}\right), V_{y}$ is the sample cylinder volume $\left(\mathrm{cm}^{3}\right), V_{Z}$ is the volume of the free space $\left(\mathrm{cm}^{3}\right), n_{c i}$ is the initial quantity of free gas in the reference cylinder at the $i$ th point (mol), $n_{y i}$ is the initial quantity of free gas in the sample cylinder at the $i$ th point (mol), $n_{B i}$ is the amount of free gas after equilibrium at the $i$ th point $(\mathrm{mol}), \Delta n_{i}$ is the change in the adsorbed gas after a single pressure swing $(\mathrm{mol}), n_{\text {toal }}$ is the total adsorption gas at the $i$ th pressure point $(\mathrm{mol}), n_{d e}$ is the total amount of desorption measured for the $j$ th time in the desorption (mol), $n_{\text {all }}$ is the total adsorption capacity at the highest test pressure (mol), $n_{i-1}$ is the quantity of the substance of the real adsorption capacity at the $(i-1)$ th point $(\mathrm{mol}), n_{A}$ is Avogadro's number $\left(6.0221 \times 10^{23}\right.$ $\left.\mathrm{mol}^{-1}\right)$, and $V_{\text {methane }}$ is the molecular volume of methane $\left(3.75946 \times 10^{-23} \mathrm{~m}^{3}\right)$. 


\subsection{Experimental Steps}

3.3.1. System Air Tightness Test. The system temperature was stabilized at a predetermined testing temperature. Then, the reference cylinder and the sample cylinder were filled with He. The pressure was slightly higher than the highest test pressure. Then, the gas injection valve and balance valve were closed. Real-time acquisition of the pressure data for the sample cylinder and reference cylinder was collected. If the pressure change within 6 hours did not exceed $1 \%$ of the initial pressure, the airtightness of the closed system is determined to be good. If the air tightness was good, the gas was vented; otherwise, the leakage points were identified and the air tightness was retested.

3.3.2. Free Space Volume Test. Based on Boyle's law, the inert gas helium was used to test the volume of the free space in the closed container after placing the shale sample inside. If the error of each test was within $\pm 0.1 \mathrm{~cm}^{3}$, then the average value was taken as the final volume of the free space.

3.3.3. Desorption Experiment. According to the test method for shale methane isothermal adsorption (revised in GBT35210.1-2017 shale methane isothermal adsorption determination method, Part 1: volumetric method) [33], high-temperature and high-pressure isothermal desorption experiments on methane with different water contents were carried out using a high-temperature and high-pressure isothermal adsorption apparatus. Desorption began at the last pressure point in the adsorption. The adsorption process included pressurization equilibrium and depressurization [34], and the specific experimental process is as follows:

(1) The balance valve and vent valve were closed, the gas injection valve was opened, and methane was injected into the reference cylinder. The pressure was adjusted to the designed initial pressure, and the pressure and temperature data for the reference cylinder and the sample cylinder were recorded after the pressure stabilized (the stable time was at least 1 hour).

(2) The balance valve was opened to allow the methane gas in the reference cylinder enter the sample cylinder. After the overall pressure was balanced (the balance time was at least $4 \mathrm{~h}$ ), the pressure and temperature data for the reference cylinder and the sample cylinder were recorded.

(3) The pressure was changed from low to high, and steps (1) and (2) were repeated until the end of the last pressure point test.

The desorption process included depressurization equilibrium and depressurization [34]:

(1) The balance valve was closed, the vent valve of the reference cylinder was opened, some of the gas in the reference cylinder was released, the vent valve of the reference cylinder was closed, and the pressure and temperature data for the reference cylinder and the sample cylinder were recorded after the pressure was balanced (the stable time was at least 1 hour).

(2) The balance valve was opened and the system pressure was allowed to balance (the balance time was at least $4 \mathrm{~h}$ ). The pressure and temperature data for the reference cylinder and the sample cylinder were recorded.

(3) The pressure was changed from high to low, and steps (1) and (2) were repeated until the end of the last pressure point test.

(4) The valve of the methane cylinder was closed, the experiment was finished, and the gas in the system was vented.

\section{Experimental Results and Discussion}

4.1. Isothermal Adsorption Desorption Curves. The modified isothermal adsorption desorption curves are shown in Figures 3 and 4 . As can be seen from the modified isothermal adsorption desorption curve, as the pressure increased, the adsorption capacity gradually increased, which conforms to the type I isothermal adsorption curve. When the pressure exceeded $30 \mathrm{MPa}$, the adsorption capacity increased slowly and stabilized.

According to the isothermal adsorption desorption curves in Figures 3 and 4, the adsorption and desorption of shale gas are not reversible processes, which is consistent with the conclusions of previous studies [35,36]. During the desorption, when the pressure decreased to the critical desorption pressure, a large amount of adsorbed gas began to desorb. Under the same pressure difference, the amount of desorption during the depressurization process was lower than that during the pressurization process. For example, when the pressure increased from $20 \mathrm{MPa}$ to $30 \mathrm{MPa}$, the increment of the adsorbed gas was about $1.0 \mathrm{~cm}^{3} / \mathrm{g}$, but when the pressure decreased from $30 \mathrm{MPa}$ to $20 \mathrm{MPa}$, the increment of the desorbed gas was about $0.4 \mathrm{~cm}^{3} / \mathrm{g}$. The increment of desorbed gas was obviously lower than that of the adsorbed gas, and the curve of the desorbed gas does not coincide with that of the adsorbed gas, and there is a lag in the gas desorption, so the adsorption and desorption cannot be the same.

In the early stage of shale gas production, the main gas source is free gas. With the rapid recovery of free gas, the reservoir pressure decreases rapidly, the adsorbed gas gradually begins to desorb, and the adsorbed gas begins to be the main gas supply source. At present, the mathematical model used to describe the change in the desorption law of deep shale gas mostly adopts the isothermal adsorption/ desorption model fitting at a lower temperature and does not strongly consider the influence of the water cut, and then, it evaluates the production and productivity of deep shale gas, which will produce a large deviation from the actual situation [37]. Therefore, it is very important to establish a desorption model suitable for describing the desorption of deep shale gas containing water to accurately predict the production and productivity of deep shale gas containing water. 


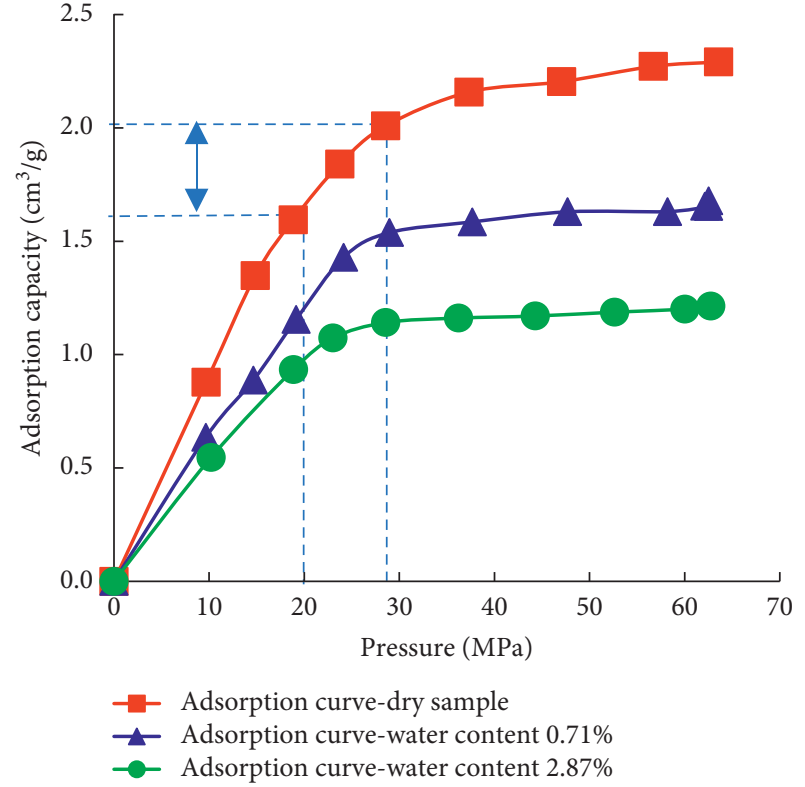

(a)

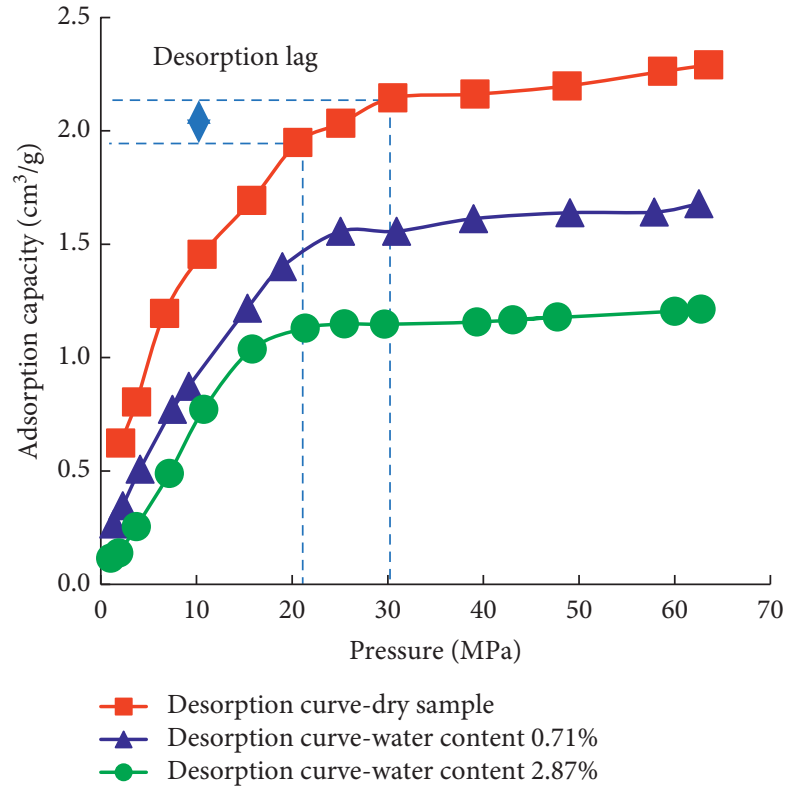

(b)

FIGURE 3: Isothermal adsorption desorption curves of shale sample GBW-1 under different water contents after volume correction. (a) Adsorption curve. (b) Desorption curve.

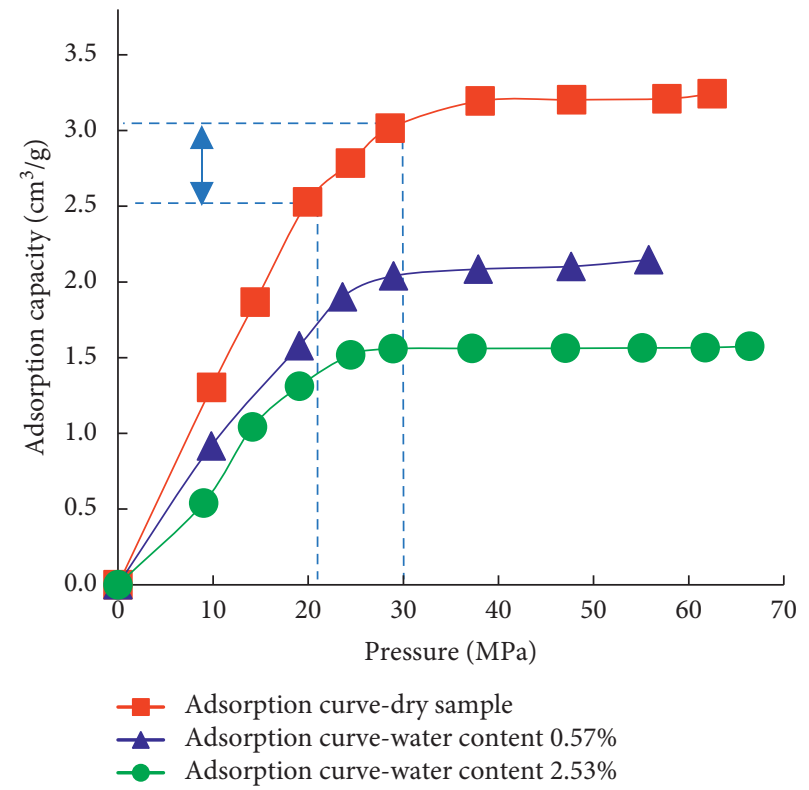

(a)

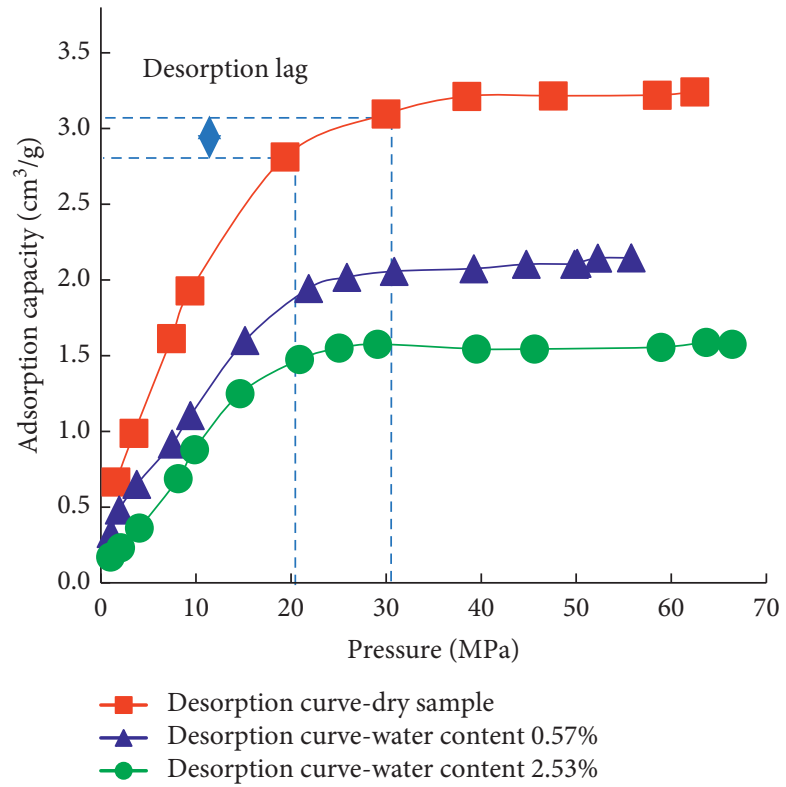

(b)

FIGURE 4: Isothermal adsorption desorption curves of shale sample LZX-1 under different water contents after volume correction. (a) Adsorption curve. (b) Desorption curve.

4.2. Model Fitting. In this study, the relationship between the water saturation and water content was determined from the porosity, water saturation, rock volume, rock density, and water density of the shale samples analyzed. The absolute amounts of desorption from shale samples GBW-1 and LZX-1 with different water contents under high-temperature and high-pressure conditions were measured and corrected using the free space volume, and the results were fitted using the desorption model (equation (9)) and MATLAB. For convenience, $m=2$ was only used to fit the data for the desorption. The fitting results are as follows.

From the fitting shown in Figures 5 and 6, it can be seen that when the pressure reached $20-30 \mathrm{MPa}$, the adsorbed gas began to desorb at $130^{\circ} \mathrm{C}$; the higher the water content, the 


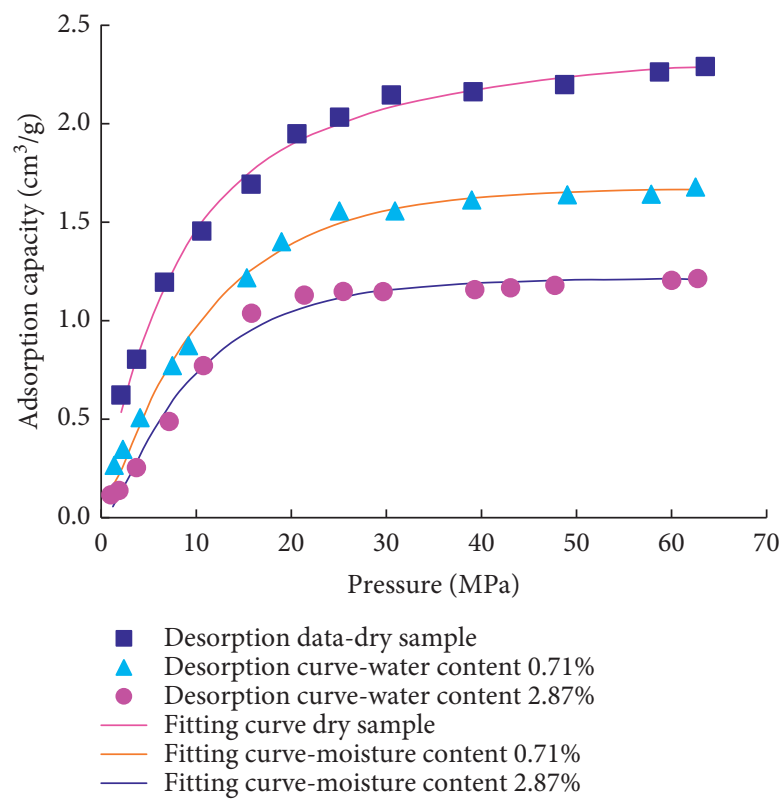

FIGURE 5: Fitting curve of the desorption data model for shale sample GBW-1 under different water contents.

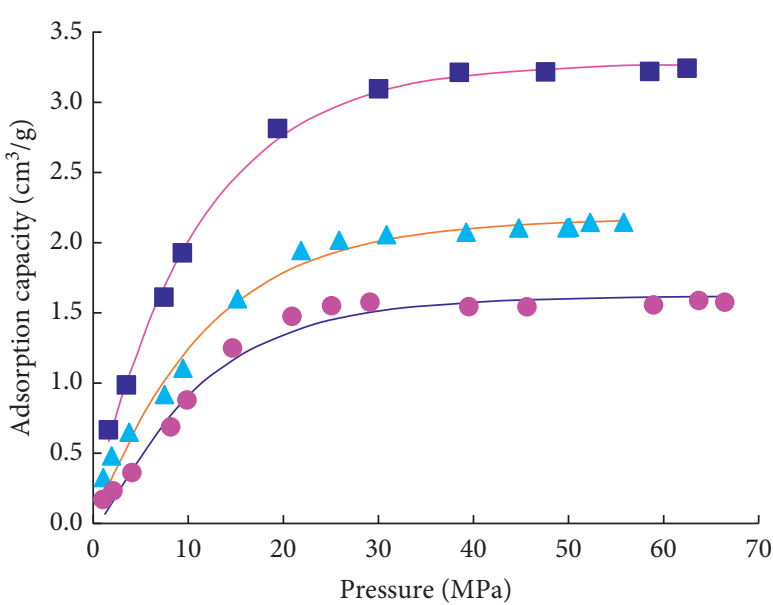

- Desorption curve-dry sample

- Desorption curve-water content $0.57 \%$

- Desorption curve-water content $2.53 \%$

- Fitting curve-dry sample

- Fitting curve-water cut $0.57 \%$

_ Fitting curve-water cut $2.53 \%$

Figure 6: Fitting curve of the desorption data model for shale sample LZX-1 with different water contents.

greater the critical desorption pressure (the pressure at which the adsorption capacity reaches the maximum during the adsorption process) of the adsorbed gas. According to the fitting data presented in Table 2, the fitting degree of the desorption model and the experimental data is $98 \%$ on average, and the overall fitting effect is good. According to the adsorption data for several deep shale gas wells in the study block (Table 3), the average distribution of the adsorption gas content obtained using the logging interpretation method in the gas producing target layer in the study block is $0.6-3.1 \mathrm{~cm}^{3}$ / g. The adsorbed gas content calculated using the model is mainly $1.1-3.3 \mathrm{~cm}^{3} / \mathrm{g}$, which is close to the range of the adsorbed gas content obtained using the field logging interpretation method. According to the residual adsorption capacity at $1 \mathrm{MPa}$, when the water content was 0 , the average residual adsorption gas content is $0.4496 \mathrm{~cm}^{3} / \mathrm{g}$. When the water content is between $0.50 \%$ and $0.71 \%$, the average content of the residual adsorbed gas is $0.1140 \mathrm{~cm}^{3} / \mathrm{g}$. When the water content is between $2.5 \%$ and $2.9 \%$, the average content of the residual adsorbed gas is $0.043 \mathrm{~cm}^{3} / \mathrm{g}$. This shows that the content of the residual adsorbed gas decreases with increasing water content, so the presence of water is conducive to the desorption of adsorbed gas to a certain extent.

4.3. Influence of Water Cut on Shale Gas Desorption. The maximum adsorption capacity and residual adsorption capacity were obtained by model fitting, and the desorption capacity and desorption rate under the residual pressure were calculated. Then, the influence of the water content on the deep shale gas desorption was analyzed. When the water content was less than $1 \%$, the influence of the water content on the desorption of the deep shale gas increased rapidly with increasing water content. When the water content was greater than $1 \%$, the influence of the water content on the desorption of the deep shale gas only changed slightly with increasing water content.

The presence of water reduces the adsorption capacity of shale (Figure 7) and promotes the desorption of adsorbed gas. When the water content is less than $1 \%$, as the water content increases, the polarity of the water molecules is stronger than that of the methane molecules, and it is easier for the water to adsorbed onto the micropores' walls, forming a certain range and thickness of water film, which prevents the gas from adsorbing onto the micropores' walls and produces competitive adsorption with the shale gas. Competitive adsorption occurs with the shale gas, and the 
TABLE 2: Fitting parameters of the isothermal shale desorption model.

\begin{tabular}{|c|c|c|c|c|c|c|}
\hline $\begin{array}{l}\text { Shale } \\
\text { sample } \\
\text { number }\end{array}$ & $\begin{array}{c}\text { Water } \\
\text { content, } M_{e} \\
(\%)\end{array}$ & $\begin{array}{c}\text { Maximum adsorption } \\
\text { capacity of micropores } \\
\left(\mathrm{cm}^{3} / \mathrm{g}\right)\end{array}$ & $\begin{array}{l}\text { Residual adsorption } \\
\text { capacity, } V_{c}\left(\mathrm{~cm}^{3} / \mathrm{g}\right)\end{array}$ & $\begin{array}{c}\text { Coefficient of } \\
\text { adsorption system } \\
(k)\end{array}$ & $\begin{array}{c}\text { Characteristic } \\
\text { adsorption energy, } E \\
(\mathrm{~kJ} / \mathrm{mol})\end{array}$ & $\begin{array}{c}\text { Fitting } \\
\text { degree, } R^{2}\end{array}$ \\
\hline \multirow{3}{*}{ GBW-1 } & 0.00 & 2.2879 & 0.3933 & 5.1367 & 14.9826 & 0.9956 \\
\hline & 0.71 & 1.6695 & 0.0977 & 5.2812 & 13.6741 & 0.9963 \\
\hline & 2.87 & 1.2081 & 0.0327 & 5.1143 & 13.9861 & 0.9837 \\
\hline \multirow{3}{*}{ LZX-1 } & 0.00 & 3.2709 & 0.5058 & 5.6137 & 18.2652 & 0.9968 \\
\hline & 0.57 & 2.1516 & 0.1302 & 5.5324 & 19.2934 & 0.9918 \\
\hline & 2.53 & 1.6134 & 0.0533 & 5.7124 & 19.2728 & 0.9708 \\
\hline Average & - & $1.2-3.3$ & - & 5.3260 & 15.9528 & 0.9891 \\
\hline
\end{tabular}

TABLE 3: Parameters for several wells in the study block.

\begin{tabular}{lccc}
\hline Well number & Average adsorbed gas content $\left(\mathrm{cm}^{3} / \mathrm{g}\right)$ & Vertical depth $(\mathrm{m})$ & Formation pressure $(\mathrm{MPa})$ \\
\hline WY1HF & $0.7-1.5$ & 3607.49 & 68.90 \\
WY9-1HF & $0.6-1.6$ & 3626.49 & 68.20 \\
WY11-1HF & 2.00 & 3728.93 & 72.30 \\
WY23-6HF & 1.30 & 3836.50 & 77.60 \\
WY29-1HF & $1.2-2.2$ & 3714.57 & 75.00 \\
WY35-1HF & $0.8-3.1$ & 3735.91 & 75.60 \\
YY1-1HF & $1.6-1.9$ & 4004.00 & 69.45 \\
YY3-1HF & $0.7-2.3$ & 4120.98 & 75.65 \\
YY2HF & $0.8-2.0$ & 4123.00 & 77.48 \\
YY6HF & $0.9-2.1$ & 4028.65 & 75.65 \\
YY7HF & $0.8-2.0$ & 3236.63 & 60.94 \\
Average & $0.6-3.1$ & 3796.65 & 72.43 \\
\hline
\end{tabular}

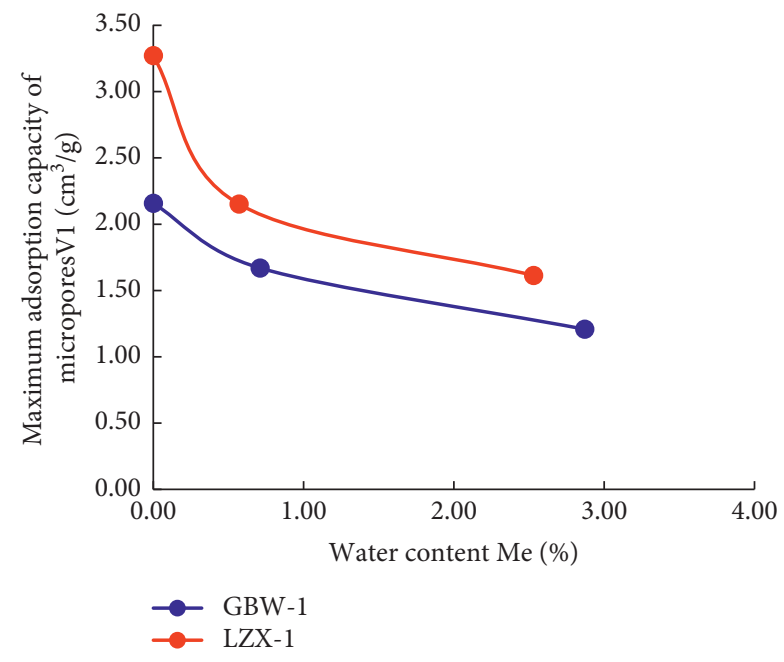

FIgURE 7: Maximum adsorption capacity under different water contents.

re-entry water will combine with the original water first, forcing the adsorbed gas to desorb during the desorption, thus improving the desorption rate (Figure 8 ). When the water content is greater than $1 \%$, because there is a lot of water in the micropores and the air pressure in the micropores is very high, as the water content increases, the amount of water entering the micropores decreases and its influence on the shale gas desorption increases but slows down. When the water content is greater than $1 \%$, because there is a lot of water in the micropores and the air pressure in the micropores is very high, as the water content increases, the amount of water entering the micropores decreases, and the degree of its influence on the shale gas desorption only changes slightly.

The water present will also interact with the clay minerals, destroy the pore structure of the clay minerals, and block the pores. Clay minerals are the important position of methane adsorption. The methane adsorption space is reduced by the interaction between the water and clay minerals, and the residual adsorption gas content decreases under the residual pressure (Figure 9). To a certain extent, it is conducive to the desorption. 


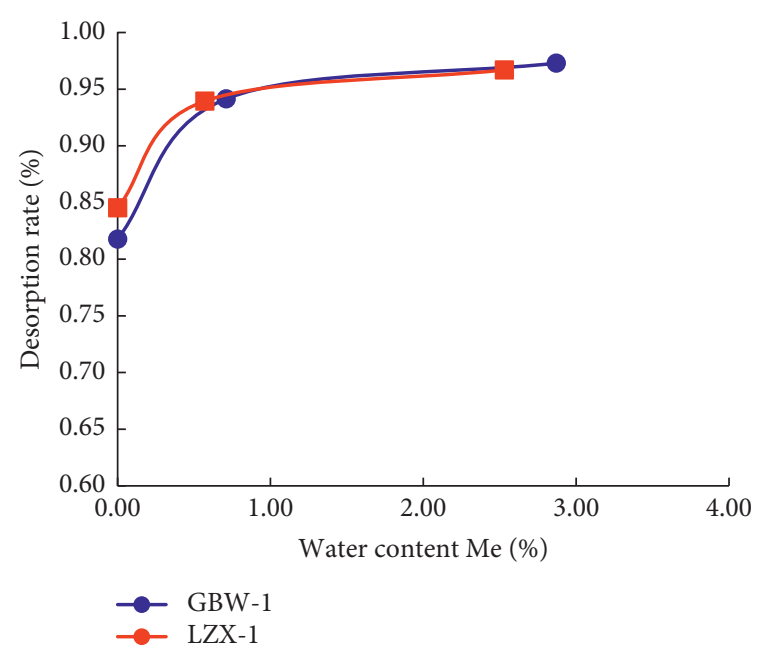

Figure 8: Desorption rate at different water contents under waste pressure.

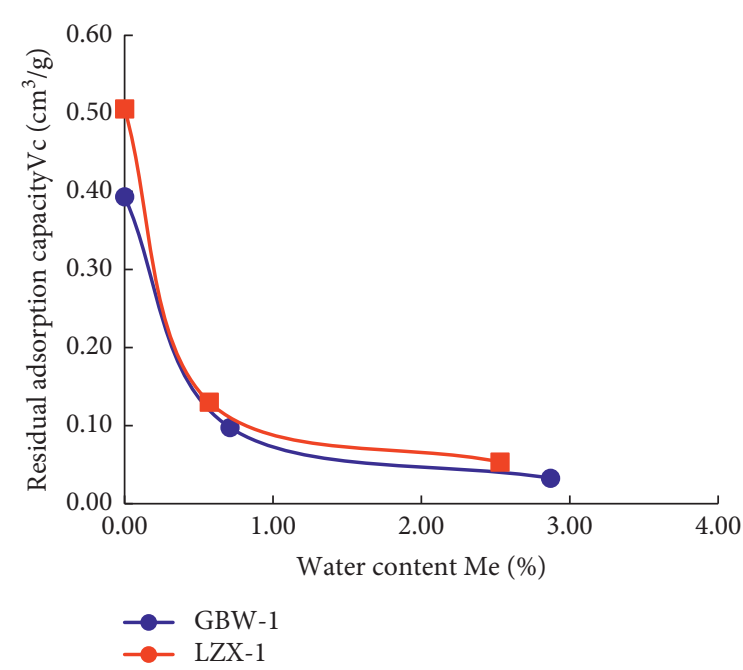

Figure 9: Residual adsorption gas at different water contents.

\section{Conclusions}

In this work, the isotherm desorption curves of $\mathrm{CH}_{4}$ on shale sampled from Western Chongqing of China were measured at $130^{\circ} \mathrm{C}$ by volumetric method. After that, the isotherm desorption data of $\mathrm{CH}_{4}$ was fitted using the improved desorption mathematical model. In addition, the influences of different water contents on the maximum adsorption capacity, residual adsorption capacity, and desorption rate were analyzed. The following conclusions can be drawn according to the above works:

(1) The improved desorption mathematical model can be used to describe the desorption process of deep shale gas containing water and has a strong applicability.

(2) It is beneficial to desorption of adsorbed gas to a certain extent with the increase of water content in the deep shale reservoir. At $130^{\circ} \mathrm{C}$, the critical desorption pressure of shale samples with different water contents was $20-30 \mathrm{MPa}$, as well as with the increase of water content, the critical desorption pressure increases slightly, and the residual adsorption decreased.

(3) The desorption curve is higher than the adsorption curve in the pressure range of 20 to $30 \mathrm{MPa}$, resulting in desorption hysteresis. Adsorption and desorption are not completely reversible processes. Therefore, the desorption needs to be described using the proposed desorption model, which can more accurately predict the production and evaluate the productivity of deep shale gas wells.

(4) With the increase of water content in the sample, the desorption rate of adsorbed gas increases; however, when the water content is greater than $1 \%$, the effect of water on the desorption of deep shale gas changes slowly.

\section{Data Availability}

The data used to support the findings of this study are included within the article. More supported data can be obtained from the corresponding author upon request.

\section{Conflicts of Interest}

The authors declare that they have no conflicts of interest.

\section{Acknowledgments}

This work was supported by the Natural Science Foundation of Chongqing City of China (Grant nos. cstc2019jcyj-zdxmX0024 and cstc2019jcyj-msxmX0507), the Technological Research Program of Chongqing Municipal Education Commission (Grant no. KJQN20200), and the graduate science and technology innovation project of Chongqing University of Science and Technology (Grant no. YKJCX2020107).

\section{References}

[1] Z. L He, H. K. Nie, D. F. Hu et al., "Geological problems in effective development of deep shale gas: a case study of Wufeng and Longmaxi Formations in Sichuan Basin and its periphery," Journal of Petroleum, vol. 41, no. 4, pp. 379-391, 2020.

[2] J. C. Zhang, J. Tao, Z. Li et al., "Resource prospect and exploration potential of deep shale gas in China," Natural Gas Industry, vol. 41, no. 1, pp. 15-28, 2021.

[3] T. L. Guo, "Progress and research direction of deep shale gas exploration and development," Reservoir Evaluation and Development, vol. 11, no. 1, pp. 1-6, 2021.

[4] C. N. Zou, Q. Zhao, D. Z. Dong et al., "Basic characteristics, main challenges and future prospects of shale gas," Natural Gas Geosciences, vol. 28, no. 12, pp. 1781-1796, 2017.

[5] C. N. Zou, Q. Zhao, L. Z. Cong, H. J. Jiang, and R. Y. Wang, "Progress, potential and Prospect of shale gas development in China," Natural Gas Industry, vol. 41, no. 1, pp. 1-14, 2021.

[6] S. B. Chen, C. Zhang, and Y. Liu, "Research progress and prospect of shale gas occurrence and its molecular simulation," Coal Science and Technology, vol. 46, no. 1, pp. 36-44, 2018. 
[7] D. Li, L. J. Zhang, Y. L. Wang, and D. T. Lu, "Compositiontransient analysis in shale-gas reservoirs with consideration of multicomponent adsorption," SPE Journal, vol. 21, no. 2, pp. 648-664, 2016.

[8] J. C. Zhang, B. Xu, H. K. Nie et al., "Potential of shale gas exploration in China," Natural Gas Industry, vol. 28, no. 6, pp. 136-140, 2008.

[9] X. Ao, Z. Qi, Z. Xiang, Z. Li, H. Qu, and Z. Wang, "Swelling of shales by supercritical carbon dioxide and its relationship to sorption," ACS Omega, vol. 5, no. 31, pp. 19606-19614, 2020.

[10] Y. J. Zhao, W. Guo, W. Xiong et al., "Study on Influencing Factors of isotherm adsorption/desorption of shale," Natural Gas Geoscience, vol. 25, no. 6, pp. 940-946, 2014.

[11] H. Y. Lin, J. Xiong, and X. J. Liu, "Study on the isothermal desorption characteristics of shale methane in Longmaxi Formation in south sichuan province," Evaluation and Development of Oil and Gas Reservoir, vol. 11, no. 1, pp. 56-61, 2021.

[12] J. Yang, G. W. Zhan, Y. Zhao, C. Y. Ren, and C. J. Qu, "Study on supercritical adsorption desorption characteristics of deep shale gas in South Sichuan," Reservoir Evaluation and Development, vol. 11, no. 2, pp. 50-55, 2021.

[13] A. F. Li, W. C. Han, H. Sun, and A. Memon, "An adsorption model with multiple factors for shale gas: taking the Wufeng Formation-Longmaxi Formation shale in southeast Sichuan as an example," Journal of China Coal Society, vol. 46, no. 3, pp. 1003-1013, 2021.

[14] X. Ao, B. Wang, H. Qu, Z. Xiang, and Z. Luo, "Swelling of shales with slickwater in carbon dioxide," Energy \& Fuels, vol. 35, no. 6, pp. 5122-5129, 2021.

[15] S. S. Gao, Z. M. Hu, W. Guo, L. Zuo, and R. Shen, "Water absorption characteristics of gas shale and the fracturing fluid flowback capacity," Natural Gas Industry, vol. 33, no. 12, pp. 71-76, 2013.

[16] Y. Q. Zhang, Study on the Effect of Water Cut on Shale Gas Adsorption, University of Petroleum of China (Beijing), Beijing, China, 2017.

[17] W. X. Yang, J. Q. Li, and Q. F. Gou, "Laboratory experiment on shale adsorption characteristics in Jiao Shiba area, Sichuan Basin," Natural Gas Geoscience, vol. 28, no. 9, pp. 1350-1355, 2017.

[18] R. Shen, H. K. Guo, Z. M. Hu, W. Xiong, and L. Zuo, "High pressure adsorption characteristics of shale gas and its influence on the storage and production law," Geoscience Front, vol. 25, no. 2, pp. 204-209, 2018.

[19] X. G. Duan, Z. M. Hu, S. Z. Gao et al., "Experiments on shale high pressure isothermal adsorption curve and gas well production dynamic characteristics," Petroleum Exploration and Development, vol. 45, no. 1, pp. 119-127, 2018.

[20] L. H. Tan, T. Ren, L. Dou, X. H. Yang, M. Qiao, and H. D. Peng, "Analytical stress solution and mechanical properties for rock mass containing a hole with complex shape," Theoretical and Applied Fracture Mechanics, vol. 114, 2021.

[21] Z. Y. Song, Y. Wang, H. Konietzky, and X. Cai, "Mechanical behavior of marble exposed to freeze-thaw-fatigue loading," International Journal of Rock Mechanics and Mining Sciences, vol. 138, 2021.

[22] X. He, W. G. Li, L. R. Dang et al., "Key technological challenges and research directions of deep shale gas development," Natural Gas Industry, vol. 41, no. 1, pp. 118-124, 2021.

[23] M. M. Dubinin and V. A. Astakhov, "Development of the concepts of volume filling of micropores in the adsorption of gases and vapors by microporous adsorbents," Bulletin of the
Academy of Sciences of the USSR Division of Chemical Science, vol. 20, no. 1, pp. 3-7, 1971.

[24] T. F. T. Rexer, M. J. Benham, A. C. Aplin, and K. M. Thomas, "Methane adsorption on shale under simulated geological temperature and pressure conditions," Energy \& Fuels, vol. 27, no. 6, pp. 3099-3109, 2013.

[25] K. A. G. Amankwah and J. A. Schwarz, "A modified approach for estimating pseudo-vapor pressures in the application of the Dubinin-Astakhov equation," Carbon, vol. 33, no. 9, pp. 1313-1319, 1995.

[26] J. Li, Z. Chen, X. Li et al., "A quantitative research of water distribution characteristics inside shale and clay nanopores," Scientia Sinica Technologica, vol. 48, no. 11, pp. 1219-1233, 2018.

[27] J. Li, X. F. Li, Y. Y. Li et al., "Methane adsorption model under pore gas liquid solid three-phase interaction in shale clay," Journal of China Coal Society, vol. 40, no. 7, pp. 1580-1587, 2015.

[28] X. Z. Xin, Study on Desorption Law of Shale Gas, China University of Petroleum (Beijing), Beijing, China, 2016.

[29] Sac, Method for Preparation of Coal Sample, China Standards Press, Beijing, China, 2009.

[30] S. W. Zhou, H. Y. Wang, and H. Q. Xue, "Difference between excess adsorption capacity and absolute adsorption capacity of shale and new calculation method of shale gas reserves," Natural Gas Industry, vol. 36, no. 11, pp. 12-20, 2016.

[31] L. Zuo, Y. Wang, W. Guo et al., "Methane adsorption on shale: insights from experiments and a simplified local density model," Adsorption Science and Technology, vol. 32, no. 7, pp. 535-556, 2014.

[32] Q. L. Zhang, "Analysis of abnormal phenomena in isothermal adsorption experiment of shale capacity method," Coal Field Geology and Exploration, vol. 43, no. 5, pp. 31-33, 2015.

[33] Sac, Determination Methods of Methane Isothermal Adsorption in Shale-Part 1: Capacity Method, China Standards Press, Beijing, China, 2017.

[34] W. Guo, W. Xiong, S. S. Gao, and Z. M. Hu, "Isotherm adsorption/desorption characteristics of shale gas," Journal of Zhong Nan University (Natural Science Edition), vol. 44, no. 7, pp. 2836-2840, 2013.

[35] S. Q. Kong, X. Huang, K. J. Li, and X. M. Song, "Adsorption/ desorption isotherms of $\mathrm{CH} 4$ and $\mathrm{C} 2 \mathrm{H} 6$ on typical shale samples," Fuel, vol. 255, 2019.

[36] Y. Liu, H. A. Li, Y. Tian, Z. Jin, and H. Deng, "Determination of the absolute adsorption/desorption isotherms of $\mathrm{CH} 4$ and n-C4H10 on shale from a nano-scale perspective," Fuel, vol. 218, pp. 67-77, 2018.

[37] R. Y. Meng, Negative Adsorption Effect of Shale Samples in Isothermal Adsorption Test and its Correction Method, China University of Mining and Technology, Xuzhou, China, 2019. 